Revista Problemas del Desarrollo, 186 (47), julio-septiembre 2016, http://probdes.iiec.unam.mx

\title{
EDITORIAL
}

\section{OBJETIVOS DEL DESARROLLO SOSTENIBLE Y LA AGENDA 2030: FRENTE A LAS POLIITICAS PÚBLICAS Y LOS CAMBIOS DE GOBIERNO EN AMÉRICA LATINA}

La Agenda para el Desarrollo Sostenible aprobada por los miembros de Naciones Unidas, el 25 de septiembre de 2015, plantea una preocupación y reflexión a realizarse por parte de organismos internacionales, gobiernos de todos los países y la sociedad civil, sobre un sendero del desarrollo frágil e incipiente. A partir de la Gran Crisis y la Gran Recesión hasta el periodo actual de stangflation, inflación cero y tasas de interés negativas, hay una preocupación por disparar de nuevo la tasa de crecimiento a nivel mundial. ¿Serán los gobiernos en el poder los que lleven a cabo la Agenda 2015-2030 con disminución en sus retenciones y restricciones al gasto social?

Se presupone que, al cerrar la brecha de las desigualdades entre los países, al interior de los mismos, entre hombres y mujeres, así como el cuidado del medio ambiente, se podrá lograr un cambio en la forma en el qué y cómo producimos, el mejoramiento y la salvaguarda del bien público, así como elevar los ingresos a partir del empleo digno.

La Agenda para el Desarrollo Sostenible ha permeado incluso a organismos financieros internacionales como el Fondo Monetario Internacional (FMI), lo cual es evidente en sus informes Global Stability Report y Fiscal Monitor Report en los que se abordaron el cumplimiento de los Objetivos del Desarrollo Sostenible (oDs), presentados en la reciente reunión de primavera de este año.

La Comisión Económica para América Latina y el Caribe (Cepal) en su Trigésimo Sexto periodo de sesiones, realizado en México, ha presentado su publicación Horizontes 2030. La igualdad en el centro del desarrollo sostenible en la que expresa la insostenibilidad del estilo del desarrollo llevado acabo hasta el día de hoy. Ahí enfatiza el cuestionamiento a la civilización actual, al modo de producción y a sus resultados donde la mano invisible ha amenazado con los recursos comunes y el bienestar de las futuras generaciones.

Todo lo anterior amerita una reflexión sobre el cumplimiento de la Agenda 2030 ante las transformaciones que se están efectuando en la región latinoamericana. El cambio democrático en Argentina y Perú acompañado de una profundización del manejo de sus políticas públicas en manos del mercado y un Estado minimalista, deja indefensa a una parte de la sociedad. 
A ello se suma el impeachment realizado recientemente en Brasil por parte de las cámaras parlamentarias elegidas democráticamente cuyo primer paso fue recortar el gasto social.

Importante es señalar cómo, después de un largo ciclo de precios altos de los commodities, el modelo primario exportador o neoextractivista se vuelve en contra de las capas sociales que fueron beneficiadas con retenciones y políticas sociales implementadas por los gobiernos de corte democrático de izquierda hasta antes de la caída de los precios de las materias primas de exportación en el año 2012. A ello se agrega un elemento nuevo en la región que diferencia en mucho el panorama actual a la "década perdida" de los ochenta. La participación de China en proyectos de inversión en infraestructura, principalmente en el Cono Sur, y demandantes de los bienes de exportación de la región latinoamericana.

Hay un sector de la academia preocupado por el cumplimiento de los oDs en el periodo señalado, pues no existe certidumbre sobre cuál será el origen del financiamiento para lograr los 17 objetivos planteados. Es a partir de la crisis de 2008 en que los bancos centrales son los que han sostenido directamente la rentabilidad de las grandes corporaciones a nivel mundial. Los mercados financieros son quienes están determinando en última instancia el precio de los commodities y con ello, profundizando el precio de las acciones y el sobreendeudamiento de las corporaciones. El ciclo de los precios altos de los países con mayor dinamismo de sus exportaciones al comercio internacional ha finalizado y teniendo como consecuencia el ajuste al gasto público y al gasto social. Y es que para cumplir con los oDs se deben de profundizar las reformas, según es la visión del FMI. La pregunta frente a la Agenda 2015-2030 queda sin respuesta, incluso en el diagnóstico realizado durante el Congreso de la Asociación de Estudios Latinoamericanos, en su 50 aniversario, llevado a cabo durante el mes de mayo en Nueva York.

El artículo "Retos de América Latina: Agenda para el Desarrollo Sostenible y Negociaciones del siglo xxı", escrito por Ana María Álvarez, tiene como eje central la discusión sobre los múltiples procesos de integración vigentes y cómo éstos pueden coadyuvar a lograr las ambiciosas metas de desarrollo sostenible plasmadas en la "Agenda 2030". Aborda las condiciones de financiamiento para que los 17 oDs plasmados en la Agenda se lleven a cabo en los próximos años. La autora destaca que en América Latina conviven modelos de integración y cooperación plurales, reconociendo que el enfoque adoptado en la conformación de la Alianza del Pacífico difiere de experiencias como la del Mercado Común del Sur (mercosur), la Alianza Bolivariana para los Pueblos de Nuestra América (ALBA), la Unión de Naciones Sudamericanas (UNASUR) 
y la Comunidad de Estados Latinoamericanos y Caribeños (CELAC). Realiza una comparación de iniciativas semejantes llevadas a cabo en Europa, Asia y África donde se encuentran los acuerdos mega-regionales como el Acuerdo de Asociación Transpacífico (TPP) y el Tratado Trasatlántico de Comercio e Inversión (TTIP).

Oscar Ugarteche en el artículo "Lecciones de la crisis del euro para la cooperación financiera regional" realiza un análisis histórico desde los planteamientos de la zona euro, los cuales permiten definir desde la formación del European Currency Unit (ECU) hasta el Tratado de Maastricht que propuso que el Eurosistema debía encargarse del "buen" funcionamiento del mecanismo de transmisión de la política monetaria.

Retoma los problemas que ha sorteado la zona euro a partir de la crisis y menciona dos visiones sobre la crisis: la primera y de orden convencional, considera que la crisis fue un problema de carácter fiscal que generó desequilibrios en la balanza de pagos; la segunda, considera el aumento del déficit y de la deuda interna como resultado interno y no como causa.

Asimismo, resalta las medidas adoptadas en torno a la crisis, y destaca el Compacto Fiscal (2012) que se refiere a mantener el equilibrio fiscal. Al final, el autor señala que es preferible pensar en la creación de un coordinador de la política macroeconómica que mire tanto lo fiscal como lo monetario, además de la existencia de dos mecanismos de financiamiento supranacional regional extraordinarios que sirvan como prestamista de última instancia para cubrir los déficit fiscales y como fondo de rescate de deuda para reducir los spreads crediticios.

"Políticas públicas en nanotecnología en América Latina", de Guillermo Foladori, parte de la hipótesis de que las políticas públicas aplicadas en nanotecnología en los países latinoamericanos han surgido principalmente por presión de organismos internacionales y no por un plan de desarrollo nacional, al no considerar los elementos de alta concentración de capitales en nanotecnología.

El desarrollo de la nanotecnología es un elemento clave para combatir la pobreza, aumentar el bienestar de la población, la salud y la competitividad de las empresas, profundizando en el desarrollo de tecnologías dirigidas al agua potable, la salud, la energía y la industria en general. Sin embargo, la producción masiva de los nanomateriales ha sido dominada por pocas corporaciones internacionales debido a las altas concentraciones de capital. Ante este panorama, la propuesta del autor se centra en la integración vertical de las cadenas de valor en nanotecnología en los mercados donde el Estado tenga monopolio, como es el caso del agua potable o los medicamentos. 
Las políticas públicas dirigidas al desarrollo de la nanotecnología se centran en el financiamiento de pequeñas empresas o centros de investigación (casi todos los países tienen grupos de investigación de alto nivel), generando, en el mejor de los casos, empresas tipo Start-up que si se consolidan, en pocos ańos serán vendidas a las grandes corporaciones o al desarrollo limitado de proyectos de investigación que no generan productos comercializables en el mercado.

El artículo de Noé Fuentes, Germán Osorio y Alejandro Mungaray "Capacidades intangibles para la competitividad microempresarial en México" sustenta que es a partir de un marco teórico de la Economía Industrial, la Nueva Economía Industrial y la Teoría de Recursos y Capacidades, los factores internos y externos de la empresa, tangibles e intangibles, que se determina la competitividad empresarial de las microempresas. Señalan que la competitividad empresarial de las microempresas está determinada por sus capacidades intangibles.

Presentan un análisis econométrico de 2671 microempresas del estado de Colima en el que se consideran el tamaño de la microempresa y el sector en el que se desenvuelve, teniendo resultados globales, por tamańo y por sector y como resultado más significativo la heterogeneidad en los factores que determinan la competitividad en la microempresa, ya que variarán dependiendo del segmento analizado, ya sea por tamaño o por sector.

"Seguridad alimentaria, autosuficiencia y disponibilidad del amaranto en México", escrito por Laura Martínez Salvador, aborda bajo el marco de la problemática alimentaria, de desnutrición en México y los cambios experimentados en política agrícola, las características nutricionales, agronómicas y productivas del amaranto.

La autora propone incentivar su producción como alternativa para contribuir a lograr la seguridad alimentaria, lo que al mismo tiempo que funcionaría como medio para combatir la desnutrición debido al alto potencial nutricional que contiene como alimento. A lo largo del artículo se aborda el tema de la seguridad alimentaria, basada en la FAO, y la importancia de la disponibilidad y de la autosuficiencia para lograrla. Expone la importancia de que un país, población o región sea capaz de satisfacer sus necesidades alimenticias mediante producción agroalimentaria local, enfatizando la necesidad de impulsar políticas públicas que ayuden a crear un mercado alimentario más equitativo y factible, tanto para consumidores, como para productores.

"México: crecimiento económico restringido y tipo de cambio, 19502014”, de Eduardo Loría, procura probar la existencia de una relación entre 
el tipo de cambio real y el crecimiento económico en México. Su hipótesis establece depreciaciones controladas en el tipo de cambio y el desaceleramiento del ritmo de crecimiento del pIB. Comienza estableciendo la relación que existe entre el tipo de cambio y el crecimiento económico, y valida la hipótesis de que el tipo de cambio real explica el comportamiento de la tasa de crecimiento del PIB.

En un segundo apartado muestra los hechos estilizados respecto al comportamiento de las dos variables de estudio en México. Con evidencia estadística permite observar que las fases de crecimiento económico del país han estado relacionadas con una apreciación del tipo de cambio, y es a partir de los años noventa cuando esta relación y cambio en los sucesos se intensifican, es decir, los episodios de recurrentes caídas en el piB estaban acompañados de una depreciación real del tipo de cambio.

Econométricamente se trata de probar usando un Vector Auto-regresivo Estructural (svar), es decir, un modelo que explique un efecto de corto y largo plazo que tiene el tipo de cambio sobre el crecimiento de la economía. Las gráficas de impulso muestran como un shock o apreciación en el tipo de cambio real propicia un aumento en el crecimiento económico por los siguientes tres periodos. En suma, el autor comprueba la hipótesis central, teórica y econométricamente.

"Los fundamentales, las posiciones netas de los especuladores y el tipo de cambio en Brasil", de los autores Armando Sánchez Vargas, Guillermo Arenas e Ignacio Perrotini tiene como objetivo principal analizar la dinámica del tipo de cambio nominal en Brasil durante el periodo 2002-2012 y demostrar que la dinámica del tipo de cambio obedece tanto a variables macroeconómicas como a microeconómicas. Para el estudio del tipo de cambio se analiza el papel de las posiciones especulativas y los fundamentales en la determinación del tipo de cambio, y se confirma que son dos canales que ayudan a explicar su comportamiento en el corto y largo plazo.

El análisis del tipo de cambio se realiza desde dos enfoques, el macroeconómico o monetario y el de microestructura, utilizando el modelo SVAR, con el que los autores encuentran que ambos enfoques son consistentes.

$\mathrm{El}$ artículo integra una revisión literaria sobre los dos enfoques bajo los que se analiza el tipo de cambio; el análisis de los enfoques de las posiciones netas de los especuladores y del paradigma monetario de la determinación del tipo de cambio; la metodología del var estructural (SVAR) utilizada en la investigación; el escrutinio empírico de las posiciones netas de los especuladores y del tipo de cambio en Brasil y las conclusiones explicando el efecto que las posiciones netas de los especuladores tienen en el tipo de cambio. 
Editorial

La sección de reseñas recomienda los siguientes libros: En la búsqueda del desarrollo regional en México, de Isaac Leobardo Sánchez Juárez, escrita por Carlos García Samaniego y Crédito y moneda: transiciones en el siglo XXI, de Alicia Girón, Eugenia Correa y Patricia Rodríguez (coords.), reseñado por Marco Antonio Vargas.

Alicia Girón

La Dirección de la Revista

Ciudad Universitaria, junio 2016 